\title{
Gene Mutations in Hereditary Breast Cancer- A Review
}

\author{
Pathima Fairoosa and Chamindri Witharana
}

\begin{abstract}
The most prevalent form of cancer in females is breast cancer. Roughly $5 \%-10 \%$ of breast cancers are hereditary, and they are associated with Germline gene mutations, inherited from parents. Germline gene mutations increase the risk of developing cancer earlier in life compared to noninherited cases (sporadic cancer). BRCA1 and $B R C A 2$ are well-studied tumour suppressor genes associated with hereditary breast cancer. Even though mutations in BRCA1 and BRCA2 are assumed to responsible the majority of hereditary breast cancers cases, many other breast cancer susceptibility genes have been identified in the last few decades. Identification of many germline mutations was possible due to advance sequencing technologies. Most of these genes are belongs to tumour suppressors and DNA damage repair gene families (DNA double-strand break repair and DNA mismatch repair). These genes play a vital role in genomic stability and cell cycle control suggesting that any alteration in these genes trigger uncontrolled growth and tumour formation. These genes are categorized according to the penetrance level, the proportion of carriers express the associated trait of the mutated gene. Mutations in high penetrance genes such as $B R C A 1, B R C A 2, T P 53, P T E N$, and SKT11 greatly increase the risk of developing breast cancer. Moderate penetrance gene such as PALB2, ATM, CHEK2, BARD1, BRIP1 and low penetrance gene such as PARP4, CASP8, TOX3 confer moderate to low increase risk of developing breast cancer. Aim of this review is to summarize genes associated with hereditary breast cancer according to their penetrance level (high, moderate and low penetrance).
\end{abstract}

Index Terms - Breast cancer, heredity, susceptibility genes, gene mutations.

\section{INTRODUCTION}

Cancer is a condition of uncontrolled cell proliferation and progressive accumulation of genetic alterations [1, 2]. Genetic alterations can be caused by specific genetic processes or by environmental factors that can trigger genetic processes. Mutations alter the mechanism of cell division and growth [3]. Although all the cancers are genetic only some are inherited and called hereditary cancer. Sporadic cancer is the other main type of cancers which occurs due to acquired genetic mutations and account for $75-80 \%$ of all cancer cases [4]. Hereditary cancers are earlyonset, occurs in younger ages compared to sporadic cancer, making it crucial to identify the germline gene mutations associated with it. Tumour suppressor gene, proto-oncogene

Published on May 30, 2020.

Chamindri Witharana, Department of Biochemistry and Molecular Biology, Faculty of Medicine, University of Colombo, Sri Lanka. (corresponding e-mail: Chamindri@bmb.cmb.ac.lk)

Pathima Fairoosa, Department of Biochemistry and Molecular Biology, Faculty of Medicine, University of Colombo, Sri Lanka.

(e-mail: fairoozamujithaba@gmail.com) and DNA damage repair gene alterations are closely related to cancer formation.

Tumour suppressor gene repairs DNA errors and control apoptosis. Mutations in these genes result in the loss of function and abnormal cell growth [4]. Proto-oncogenes control cell proliferation. Mutation in proto-oncogene transfer proto-oncogene into oncogenes resulting in uncontrolled cell proliferation. This is called a gain of function mutation which increases the expression of the gene. Point mutation, translocation and amplification lead to oncogene activation. Genomic DNA continuously exposed to various geno-toxicants that may cause DNA lesions, mutations and DNA strand breaks. DNA repair mechanisms namely DNA mismatch repair, recombination repair (homologous recombination and nonhomologous endjoining) and excision repair (nucleotide excision repair and base excision repair) protect the genetic information in genome and ensure genomic stability [5]. Mutations in DNA repair genes lead to genomic instability and accumulation of unrepaired, damaged DNA strands. Accumulation of unrepaired, damaged DNAs may direct the cell to apoptosis or carcinogenesis [5].

\section{BREAST CANCER}

The most prevalent form of cancer in females is breast cancer $(\mathrm{BC})[6,7]$, representing nearly a quarter $(25 \%)$ of all cancers with an estimated 2.1 million new cases diagnosed in 2018 [8]. Incidence and death are increasing annually and $12.5 \%$ of women are diagnosed with $\mathrm{BC}$ in her lifetime [6]. There has been a rapid increase in BC incidence globally and estimated to increase by another $25 \%$ by the year 2020 [9]. Environmental and genetic risk factors can induce $\mathrm{BC}$ in human. Environmental factors that can induce $\mathrm{BC}$ are radiation, synthetic chemicals (Organo-chlorines), oral contraceptives, hormone replacement therapy, pregnancy, menstrual history, lack of exercise, alcohol consumption, benign breast disease and obesity [10]. BC shows strong hereditary predisposition and certain heritable syndromes associate with increased risk of $\mathrm{BC}$ [11]. Individual's BC risk increases proportionally with a family history of the disease [9]. At least $10 \%$ to $15 \%$ of all the $\mathrm{BC}$ cases are inherited and explained by germline genes mutations in critical genes. These mutations are transmitted in an autosomal dominant manner [10-12]. BReast Cancer 1 (BRCA1) and BReast Cancer 2 (BRCA2) genes are the most studied genes relation to $\mathrm{HBC}$ for the past few decades [10, 13]. Identification of $B R C A$ mutations has been used as one of the strongest $\mathrm{HBC}$ predictor [14]. However, only $20 \%$ $30 \%$ of $\mathrm{HBC}$ are due to mutations in $B R C A 1$ or $B R C A 2$. Additional genes such as TP53, PTEN, STKII, CHEK2, $A T M, P A L B 2$ and BRIP2, associated with HBC haven been 
identified with the advancement in molecular genetics and linkage analysis $[15,16]$. Completion of the human genome project and the development of gene wide association studies (GWAS) led to the identification of even more BC susceptibility genes with higher allele frequencies [16].

Emerging studies in the last two decades have been identifying many $\mathrm{HBC}$ susceptibility genes to improve disease diagnosis. HBC incidence and deaths can be decreased by improving early deduction [7]. Early identification of people having a higher risk of developing $\mathrm{BC}$ due to germline mutations may lead to better treatment, disease prevention strategies and overall survival benefit. This review will summarize the current understanding of HBC susceptibility genes.

\section{ClassificAtion OF BREAST CANCER SUSCEPTIBILITY GENES}

An estimate of mutation-associated cancer risk is termed as penetrance [17]. This can be further explained as proportions of individuals carry a particular gene mutation as well as express the associated phenotype [16]. There is an inverse relationship between the risk conferred by a variant in $\mathrm{BC}$ susceptibility genes and frequency of the variant in the population with some expectations [18]. Variants generally categorized as rare high-risk mutations, rare moderate-risk mutations and common low-risk mutation [15]. High-penetrance gene mutations such as BRCA1, BRCA2, TP53, PTEN, STK11, and CDH1 are associated with a relative risk of $\geq 5$. Moderate-penetrance gene mutations such as ATM, CHEK2, PALB2, and BRIP1 are associated with a relative risk of $\geq 1.5$ and $<5$, whereas lowpenetrance gene mutations are associated with a relative risk of $\geq 1.01$ and $<1.5$ with the highest allele frequencies [19].

\section{HIGH PENETRANCE GENE MUTATIONS}

\section{A. BRCA1 and BRCA2}

BRCA1 and BRCA2 genes were identified in 1994 and both of them have been well studied concerning cancer development for the last few decades. BRCA1 and BRCA2 are included in clinical risk assessment to find the probability of developing $\mathrm{BC}[17,20]$. Mutations in $B R C A 1$ and $B R C A 2$ genes occur in approximately 1:400 and 1:800 women in a general population [15]. BRCAl mutation carriers have a lifetime risk of developing $\mathrm{BC}$ and ovarian cancer of $45-75 \%$ and BRCA2 mutation carriers have a lifetime risk of developing $\mathrm{BC}$ and ovarian cancer of $18-40 \%$. [13]. Population studies showed that $B R C A 1$ and BRCA2 mutations with a family history of $\mathrm{BC}$ confer higher risk compared to the general population. Women having a mutation in BRCA1 and BRCA2 and having multiple affected relatives with a young age of diagnosis have $80 \%$ to $90 \%$ lifetime risk of developing BC [17].

$B R C A 1$ and BRCA2 are tumour suppressor genes and maintain genomic stability $[6,21] . B R C A 1$ and $B R C A 2$ genomic structures are complex and there is no homology between the coding regions [22].

Chromosome $17 \mathrm{q} 12-21$ is the genomic location of human BRCA1 [21, 23]. BRCA1 contains 24 exons encoding a large nuclear phosphoprotein $(220 \mathrm{kDa})$ that has 1,863 amino acids [10, 22, 24]. Chromosome 13 (13q12.3) is the genomic location of BRCA2. BRCA2 contains 27 exons encode large protein $(380 \mathrm{kDa})$ which has 3,418 amino acids $[25,26]$. $B R C A 1$ and BRCA2 both have large exon 11 as shown in Figure 1. There are three domains in $B R C A 1$, play a major role in interaction with other proteins and subcellular localization of BRCA1. The middle region; Exon 11-13 encodes nearly $60 \%$ of BRCA1 protein and highly responsible for tumour suppressor activity of BRCA1. A large percentage of clinically important mutations are observed at exons 11-13. This region interacts with retinoblastoma protein $(\mathrm{Rb}), \mathrm{c}-\mathrm{Myc}, \mathrm{RAD} 50$, and RAD51 as shown in figure 2. Two nuclear localization sequences (NLS) are located in between amino acids 501-507 and 607-614. NLS promotes the interaction of importin-alpha and this interaction, which negotiate BRCA1 transport to the nucleus from the cytosol [21].

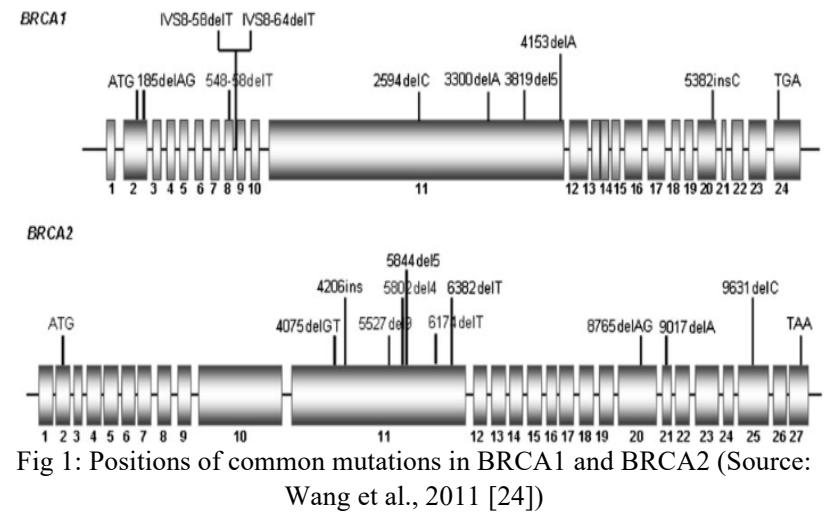

N-terminal RING domain encoded by exons 2-7 (amino acids 1-109) and BRCA1 C-terminus encoded by exons 1624 (amino acids 1650-1863). The RING finger motif (residue 24-64) is in the RING domain of BRCA1 and it is highly conserved for ubiquitination pathway. The RING finger motif is important for E3-ubiquitin ligase activity of BRCA1. BARD1 is another RING containing protein which interacts with $B R C A 1 \mathrm{~N}$-terminal ring [21, 27]. C-terminal domain/ BRCT domain interacts with ATM, ATR, P53 and BACH1. ATM and ATR are DNA damage activated kinases and $P 53$ and $B A C H 1$ are transcriptional regulators [21].

BRCA1 is a multi-functional protein interacts with different proteins to play role in different cellular pathways such as apoptosis, DNA damage repair, cell-cycle arrest, transcriptional activation and tumorigenesis [21]. The major function of BRCA1 is to maintain genomic stability through DNA damage signaling and DNA repair [22]. BRCA1 and BRCA2 are involved double strand (DS)-DNA break repair by homologues recombination (HR) [1]. Upon DNA damage, BRCA1 will associate with RAD51 and localized to the damaged region. BRCA1 becomes phosphorylated. BRCA2 forms a complex with RAD51 of the downstream of 
BRCA1. The primary function of BRCA2 is to facilitate HR [22]. Cells cannot repair DS-DNA breaks by error-free HR when $B R C A 1$ and $B R C A 2$ are mutated this leads to errorprone non-homologous end joining (NHEJ) and genomic instability [28]. Expression of BRCA1 and BRCA2 are high in S-phase of the cell cycle indicating a function in genomic stability during DNA replication [22].

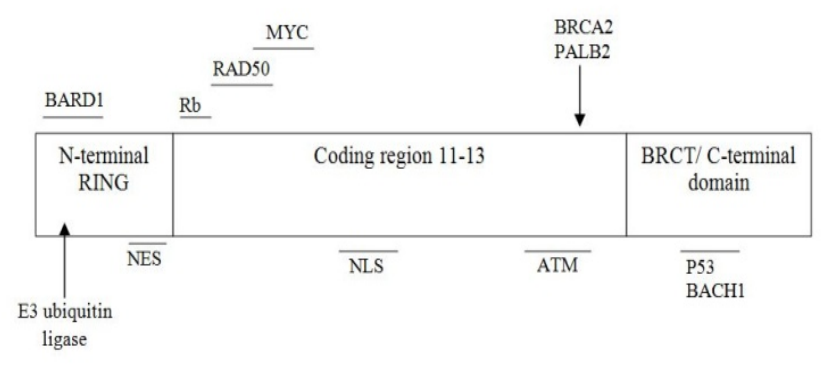

Fig 2: BRCA1 gene map

In addition to its role in HR, BRCA1 interacts with at least 13 different tumour suppressor proteins and mismatch repair proteins to form a macromolecular protein complex known as BRCA1-associated genomic surveillance complex (BASC) which regulate DNA damage repair and cell cycle checkpoints [28]. BASC includes ATM, RAD50, MRE11, NBS1 and DNA mismatch repair proteins (MLH1, PMS2, MSH2 and MSH6) [10, 22]. BRCA1 is also implicated in transcription-coupled excision repair, chromatin remodeling and ubiquitination process with the help of BARD1, by which proteins are tagged for degradation by the proteasome $[6,23,29]$.

$B R C A 2$ has eight internally repeating sequences called BRC motif. BRC motif is the major domain to interact with RAD51. BRCA2 also involved in DNA double-stranded repair. BRCA2 binds to single-stranded DNA. BRCA2 interacts with RAD51 recombinase to stimulate strand invasion which is a critical step in homologous recombination [30]. BRCA1 and BRCA2 have some similarities in exon structures. But there is no significant sequence homology between them. BRCA2 is responsible for nuclear localization signal in human. BRCA2 is also a transcriptional co-regulator as BRCA1. BRCA2 is found to be interacting with SMAD3 and form a complex that coactivated Smad3-dependent transcriptional activation of plasminogen activator inhibitor-1 (PAI-1). It collaborates in androgen-mediated transcription with the histone acetyltransferase. Structure of the $\mathrm{C}$-terminal domain of $B R C A 2$ is known and many tumours derived mutations were observed in this domain. C-terminal domain has DNA binding properties. The BRCA2 colocalizes with RAD51 during meiosis on chromosome axes like in BRCA1. This association shows the participation of BRCA2 in the repair of DNA damage by homologous recombination pathway [21].

Pathogenic mutations can occur throughout the BRCAl and $B R C A 2$. The most common type of mutations is frame-shift mutations (small deletion or insertion) or nonsense mutations resulting in protein truncation $[24,26]$. Mutations affecting splice-site, large genomic rearrangement as well as not well-understood missense, silent mutations and polymorphisms were reported [22]. A germline mutation in $B R C A$ genes only represents the 1st hit of the Knudson's two-hit hypothesis. Carriers of mutations have one germline hit (mutated and inherited copy of $B R C A$ ) [22, 26].

BRCA1 mutation carrier has $60-70 \%$ lifetime risk of developing $\mathrm{BC}$ and $B R C A 2$ mutation carrier has a $45-55 \%$ risk of developing $\mathrm{BC}$ [28]. However, the contribution of $B R C A$ mutations to develop $\mathrm{BC}$ within any specific population depends on prevalence and penetrance. Mutations in $B R C A$ genes occur with different frequencies across the ethnicities [7]. Male BRCA2 mutation carriers confer a lifetime risk of prostate, breast, and pancreatic cancers [25]. $60 \%$ to $80 \%$ BRCA1- related tumours display a triple-negative barest cancer phenotype. BRCA2 -related tumours usually express estrogen and progesterone receptors and tend to have similar features to sporadic BCs [10].

It was assumed that $B R C A 1$ and $B R C A 2$ germline mutations are the common mutations found $\mathrm{HBC}$. However, the latest studies demonstrated that mutations in BRCA1 and BRCA2 only account for 25 to $28 \%$ of HBC [22]. Mutations in $B R C A 1$ and $B R C A 2$ were not found in all HBC. Many studies have reported evidence for germline mutations in other rare high penetrance genes.

\section{B. TP53}

Tumour protein 53 (TP53) is a tumour suppresser gene located on the short arm of chromosome 17p13.1 and contains 11 exons encodes tumour protein p53 which is composed of 393 amino acids [25, 31, 32]. p53 consists of four domains: i) an N-terminal sequence (transactivation) domain that is involved in the regulation of the target gene transcription; ii) a core domain that recognizes specific DNA sequences; iii) an oligomerization domain that is responsible for the tetramerization of the protein (the functional form of $\mathrm{p} 53$ ); iv) and a C-terminal domain that is essential for the regulation of p53 activity [32]. The p53 protein is situated in the cell nuclei and binds directly to DNA and responds to many cellular stresses including chemicals, radiation and ultraviolet rays from sunlight to regulate the expression of target genes. Also, p53 participates in the regulation of cell cycle, apoptosis, senescence and DNA repair $[31,33]$. If the DNA is mutated or damaged and cannot be repaired, p53 transmits a signal, which triggers cell apoptosis and prevents cells from dividing and developing into tumours [32]. Loss or disruption of p53 function due to mutation can cause uncontrolled cell proliferation and cancer. Some p53 mutant gains new functions and prevent binding of wild type p53 to the promoter of the target gene [31]. Missense and proteintruncating variants of RP53 are also associated with increased risks of $\mathrm{BC}$ [34]. Mutations in this gene cause LiFraumeni syndrome and affect adults and children. This high penetrance gene predisposes for a wide spectrum of tumours, including sarcomas, adrenocortical carcinomas, brain cancer, and very early-onset BC [10]. The majority of somatic mutation TP53 are single-base substitutions and spread over exon 5 to 8 . TP53 mutation carriers have 18 to 
60 fold increased risk for early-onset breast BC (diagnosed before the age of 45) when compared to the general population [10]. Most BCs caused by TP53 mutation are human epidermal growth factor receptor (HER2) positive and estrogen receptor (ER)-positive [28]. Expression of genes associated with the regulation of cycle and apoptosis are up-regulated in the absence of P53, BRCA1 and BRCA2 proteins [33].

Studies have demonstrated $2-3 \%$ of patients with inherited mutations (early-onset) and $\sim 40 \%$ of somatic mutations in TP53 of all cases of BC cases. Somatic mutation in TP53 occurs more frequently than inherited mutations. Furthermore, TP53 is a polymorphic gene and 80 single nucleotide polymorphisms (SNPs) have been identified in human populations to date. $90 \%$ of SNPs are situated in introns or outside splice sites. However, the potential role of SNPs in BP risk is not well known [32].

\section{TABLE I: HEREDITARY BREAST CANCER HIGH PENETRANCE GENES}

\begin{tabular}{|c|c|c|}
\hline Gene & Location & Function \\
\hline$B R C A 1$ & $17 q 12-21$ & $\begin{array}{l}\text { Tumour suppressor, DNA double-strand } \\
\text { break repair via homologous } \\
\text { recombination, BRCA1-associated } \\
\text { genomic surveillance complex formation. }\end{array}$ \\
\hline$B R C A 2$ & $13 q 12.3$ & $\begin{array}{l}\text { Tumour suppressor, DNA double-strand } \\
\text { break repair. }\end{array}$ \\
\hline TP53 & $17 \mathrm{p} 13.1$ & Tumour suppressor (cell growth regulator) \\
\hline PTEN & $10 \mathrm{q} 23.3$ & $\begin{array}{l}\text { Tumour suppressor, mutation associated } \\
\text { with improper cell cycle arrest }\end{array}$ \\
\hline SKT11 & $19 \mathrm{p} 13.3$ & $\begin{array}{l}\text { Tumour suppressor, associated with } \\
\text { apoptosis; also a negative regulator of the } \\
\text { mTOR pathway }\end{array}$ \\
\hline $\mathrm{CDH1}$ & $16 \mathrm{q} 22.1$ & Epithelial cell-cell adhesion molecule \\
\hline $\begin{array}{l}R A D 51 C \\
R A D 51 D\end{array}$ & $\begin{array}{l}17 \mathrm{q} 22 \\
17 \mathrm{q} 12\end{array}$ & $\begin{array}{l}\text { Associated with DNA double-strand break } \\
\text { repair via homologous recombination }\end{array}$ \\
\hline $\begin{array}{l}\text { MLH1, } \\
\text { MSH1, } \\
\text { MSH6, } \\
\text { PMS2 }\end{array}$ & $\begin{array}{l}2 \mathrm{p} 22.2 \\
2 \mathrm{p} 21-\mathrm{p} 16 \\
2 \mathrm{p} 16.31- \\
7 \mathrm{p} 22\end{array}$ & DNA mismatch repair \\
\hline
\end{tabular}

\section{PTEN}

Genomic location of phosphatase tensin homologue gene (PTEN) is chromosome 10q23.3. PTEN, tumour suppressor gene encodes PTEN protein that controls chromosomal integrity through direct interaction with the kinetochore component centromere protein $\mathrm{C}$ and regulation of $\operatorname{Rad} 51$ homolog expression. PTEN has also been shown to regulate the anaphase-promoting complex (APC)-cdh1/ Hct1 homolog (CDH1) tumour suppressive complex [35]. PTEN is a phosphatidylinositol 3-phosphatase and functions as a tumour suppressor by tensin homolog negatively regulating AKT signaling pathway [36]. Mutations in this gene lead to uncontrolled cell growth. PTEN mutations can cause many syndromes including Cowden Syndrome; an autosomal dominant disorder. Patient with Cowden syndrome has a high risk of benign and malignant tumours of the breast, thyroid and endometrium at high frequency $[10,36]$. Among these cancers patient with $\mathrm{BC}$ have a lifetime risk of up to $50 \%-85 \%$ [28].

\section{D. $C D H-1$}

The E-cadherin gene (CDH1) is a calcium-dependent cellcell adhesion molecule in junctions between epithelial cell encoded by $C D H-1$ a tumour suppressor gene. Germline mutation in this gene can cause lobular gastric cancer and invasive lobular carcinoma of the breast but not ductal $\mathrm{BC}$ [37]. $\mathrm{CDH1}$ has clear evidence for its association with $\mathrm{BC}$ [34]. A female with $\mathrm{BC}$ has at least a $1 \%$ chance of carrying $\mathrm{CDH}-1$ mutation [27]. $\mathrm{CDH}-1$ female mutations carriers have a lifetime risk of up to $40 \%$ to $54 \%$ lifetime risk of developing lobular BC [10].

\section{E. STK11}

Genomic location of the tumour suppressor Serine/threonine kinase gene (STK11) in human is 19p13.3. m-TOR pathway is negatively regulated by this gene [28]. This gene is associated with apoptosis and cell cycle regulation. STK11 act as cell polarity regulator. Mutation in this gene can cause Peutz-Jeghers syndrome, an autosomal dominant syndrome characterized by the growth of polyps in the gastrointestinal tract, pigmented macules on the skin and mouth $[10,36]$. Additionally, a mutation in this gene increases the risk of cancer including breast, colon, stomach, small intestine, pancreas and ovary. The lifetime risk for developing any cancer including breast BC by mutated STK11 in a female is up to $85 \%$ [10].

\section{F. RAD51C and RAD51D}

RAD51C and RAD51D genes encode RAD51c and RAD51D proteins. RAD51C and RAD51D are two of the five paralogs of a RAD51 protein family involved in DNA DS-repair and required for both types of the repair processes, NHEJ and HR [36]. RAD51 family members are similar to bacterial RecA and Saccharomyces cerevisiae Rad51 [10]. These genes are known to be interacting with BRCA1 and BRCA2 [28]. Loss-of-function mutations in $\mathrm{RAD}$ genes are associated with developing $\mathrm{BC}$ and ovarian cancer at high and categorized under high penetrance genes [22]. Pathogenic RAD51C mutations have also been identified in BRCA1/2 mutation-negative hereditary breast and ovarian cancer (HBOC) families. A biallelic mutation or a homozygous missense mutation in RAD51C was reported to cause Fanconi anaemia-like phenotype $[10,36]$. A single nucleotide ( $\mathrm{G}$ to $\mathrm{C}$ ) substitution in the 50-untranslated region of the RAD51 gene has been found to modulate $\mathrm{BC}$ risk [38].

\section{G. MLH1, MSH2, MSH6 AND PMS2}

MutL homolog 1 (MLH1), mutS homolog 2 (MSH2), mutS homolog 1(MSH6) and postmeiotic segregation increased 2 $(P M S 2)$ are mismatch repair genes [36]. Proteins encoded by these genes are associated with BRCA1 [39]. Main 
functions of these genes are the elimination of single-base mismatches and insertion-deletion of loops that arise during DNA replication and maintaining genomic integrity. MSH2 protein forms a heterodimer with either MSH6 or MSH3. It depends on the type of lesion to be repaired. Correction of single-base mispairs required MSH6 and the correction of insertion-deletion loops required both MSH3 and MSH6. PMS2 and MLH2 are heterodimer coordinate mismatch recognition complex and other proteins necessary for mismatch repair such an exonuclease 1 (EXO1), possibly helicase(s), proliferating cell nuclear antigen (PCNA), single-stranded DNA-binding protein (RPA), and DNA polymerases. PMS2 and MLH can also form heterodimers with MLH3 and PMS1 [40]. Germline mutations in $M L H 1$, MSH2, MSH6 and PMS are associated with high BC risk and categorized under high penetrance genes [25]. Singlebase mismatches correction and insertion-deletion loop correction requires PMS2. There are no sufficient research data on PMS1 [40].

\section{MODERATE PENETRATE GENES}

\section{A. PALB2}

PALB2 is also known as FANCN (Fanconi anaemia gene) is a moderate penetrance gene. However, the penetrance of this gene can be altered by environmental factors and lifestyle. The major role of PALB2 is DS-DNA repair by HR $[10,28]$. Next to BRCA1 and BRCA2 mutations, $P A L B$ mutation is the most common in BC. Some mutations in PALB2 have a high risk for $\mathrm{BC}$ even though $P A L B$ categorized under moderate penetrance gene [41]. Earlier, PALB2 was known as BRCA2 interacting protein that plays a key role in BRCA2 functions. Later, its interaction with BRCA1 was also identified. Loss of function mutation in PLAB2 is associated with an increase in the risk of BC. The recent research on PALB2 reported that some BRCA1 and BRCA2 mutation carrier patient with $\mathrm{BC}$ had a loss of function mutation in $P A L B 2$. The risk of $\mathrm{BC}$ for female $P A L B 2$ mutation carriers, as compared with the general population, was eight to nine times as high among those younger than 40 years of age, six to eight times as high among those 40 to 60 years of age, and five times as high among those older than 60 years of age [42]. Mutations in $P A L B 2$ increase the risk of cancers including BC. PALB2 strongly associated with the risk of ER-positive and ERnegative subtypes [43]. Mutations in this gene can cause BC in male [28].

\section{B. ATM}

Ataxia-telangiectasia mutated gene $(A T M)$ is moderatepenetrance $\mathrm{BC}$ susceptibility genes and confers a 2-fold to 3 -fold increase in the risk of BC compared to the general population [41]. This gene encodes p13k-related protein kinase which as multiple functions. ATM interacts with $\mathrm{C}$ terminal end of BRCA1 that is important in DNA damage repair [28, 43]. Homozygous or compound heterozygous ATM mutations cause ataxia-telangiectasia syndrome [10,
28]. Many studies have reported that mutations in this gene increase the risk of $\mathrm{BC}$ [43]. BC risk of ATM mutation carriers is $50 \%$ and higher for younger women less than 50 years [28]. ATM interacts with C terminal end of BRCA1. This interaction is important in DNA damage repair [21]. ATMp.Val2424Gly has a higher risk of BC than truncating variants [34].

\section{CHEK2}

Checkpoint kinase 2 (CHEK2) is a $\mathrm{BC}$ moderate penetrance gene [42]. However, it may regulate by environmental factors and lifestyle to cause cancer [28]. This gene encodes a checkpoint kinase. This protein kinase is known to interact with DNA repair proteins and cell cycle regulation [43]. CHEK2 is known as an upstream regulator of BRCA1. CHEK2 has 3 domains; SQ/TQ cluster domain, Forkheadassociated (FHA) domain and Ser/Thr kinase domain [10]. $A T M$ and $A T R$ activate $C H E K 2$ as a response of DNA DS breaks or replication stress. It activates cell cycle checkpoint and increases DNA repair efficiency by full activation and trans-autophosphorylation of CHEK2. Phosphorylation of threonine 68 of CHEK2 is catalyzed by ATM and ATR. Phosphorylation of CHEK2 activates P53 tumour suppressor, CDC25 family proteins and serine 988 of BRCA1 [44]. Germline mutations in CHEK2 play a significant role in HBC. 1100 delC deletion in CHEK2 is a common type of mutation and it increases the susceptibility of $\mathrm{BC}$ by 2 -fold [10, 43]. 1100delC mutation of this gene is found in patients of northern and eastern European ancestry. CHEK2 mutation has a lifetime risk of $37 \%$ for bilateral $\mathrm{BC}$ and male $\mathrm{BC}$. This mutation can be found in $5 \%$ of $\mathrm{BC}$ patients without BRCA mutations [28]. CHEK2 missense variant p.Ile157Thr has a lower risk of $\mathrm{BC}$ than the CHEK2 c.1100delC truncating variant $[10,35]$.

\section{BARDI}

BRCA1-associated RING domain (BARDI) was identified initially as a ring containing protein interacts with BRCA1. Ring figure motifs of $B R C A 1$ and $B A R D 1$ are important in their interaction [27, 45]. BRCA1-BARD1 interaction has a role in RNA processing, DNA repair, cell cycle regulation and apoptosis [10, 27]. Germline mutations of BARD1 have been found a few cancers including BC. BARD1 mutation confers an increased risk of developing $\mathrm{BC}$ with family history. The risk factors and percentages of BRAD 1 mutations require further analysis [10].

\section{E. BRIPI}

BRCA1 interacting protein 1 gene (BRIP1) is located on chromosome 21 . The protein encoded by this gene interacts with BRCA1. This interaction promotes error-free DNA DS repair. BRIPI also known as FANCJ (Fanconi anaemia gene) and $B R C A 1$ associated C-terminal helicase $(B A C H 1)$. BRIP1 repair damaged DS DNA break and maintain chromatin stability [45]. BRIP1 has been reported as a BS susceptibility gene [27]. Missense and truncating mutations of this gene were detected in different population. Mutated 
BRIP1 increase BC and ovarian cancer risk by two-fold [9]. This gene link to mismatch repair (MMR) complex and associated with cross-linking repair. Germline mutation in this gene leads to error-prone NHEJ [35].

\section{F. MRN Complex (MRE11, RAD50, NBS1)}

MRE11, RAD50 and NBS1 are genes composed a protein complex called MRE11-RAD50 - NBS1 (MRN) complex. The overall function of this complex is genomic stability. This complex can sense DS breaks and process DS break repair in early-stage $[10,28]$. Mre11 involve in DNA recombination, cell cycle regulation and telomeres maintenance. RAD50 is known as highly conserved DNA DS break repair factor. Only a small disruption MRN complex can have effects on genomic stability. Mutations of all three genes in the complex have been identified [10]. Mutations in $N B N$ cause Nijmegen breakage syndrome, an autosomal recessive chromosomal instability syndrome characterized by microcephaly growth retardation, immune deficiency and cancer predisposition including BC [47]. Frequency of mutation in these genes widely varies across populations [28].

\section{TABLE II: HEREDITARY BREAST CANCER MODERATE PENETRANCE GENES}

\begin{tabular}{lll}
\hline \hline Gene & Location & Function \\
\hline PALB2 & $16 \mathrm{p} 12.1$ & $\begin{array}{l}\text { Binding partner and localizer of BRCA2 } \\
\text { associated with DNA homologous } \\
\text { recombination repair }\end{array}$ \\
\hline ATM & $11 \mathrm{q} 22.3$ & $\begin{array}{l}\text { Associated with DNA double-strand break } \\
\text { repair and cell cycle progression }\end{array}$ \\
\hline CHEK2 & $22 \mathrm{q} 12.1$ & $\begin{array}{l}\text { Associated with DNA double-strand break } \\
\text { repair; also phosphorylates BRCA1 }\end{array}$ \\
\hline BARDI & $2 \mathrm{q} 34-\mathrm{q} 35$ & $\begin{array}{l}\text { DNA repair, apoptosis, RNA processing } \\
\text { and cell cycle regulation }\end{array}$ \\
\hline BRIP1 & $17 \mathrm{q} 22-\mathrm{q} 24$ & $\begin{array}{l}\text { Encodes protein serving as a binding } \\
\text { partner of BRCA1 }\end{array}$ \\
\hline MRE11, & $11 \mathrm{q} 21$, & $\begin{array}{l}\text { Associated with DNA double-strand break } \\
\text { repair }\end{array}$ \\
RAD50, & $5 \mathrm{q} 31$, \\
$8 \mathrm{q} 21.3$ & $\begin{array}{l}\text { Homologous recombination repair of } \\
\text { double-stranded DNA breaks }\end{array}$ \\
\hline$X R C C 2$ & $7 \mathrm{q} 36.1$ & $\begin{array}{l}\text { Activates CHK1, TP53, and BRCA1 and } \\
\text { RAD. }\end{array}$ \\
\hline$A T R$ & $11 \mathrm{q} 22.3$ & $\begin{array}{l}\text { Governs the G2/M transition of the cell } \\
\text { cycle. }\end{array}$ \\
\hline \hline
\end{tabular}

\section{G. XRCC2}

$X R C C 2$ (x-ray repair cross-complementing gene-2) encodes a protein is which is a RAD51 paralog. XRCC2 involves in homologous recombination repair of DS DNA breaks [48]. Even though mutations in this gene are uncommon, it has increased risk of BC with family history [43]. Proteintruncating variant, one-base-pair deletion and p.R188H missense mutations were reported which may have increased $\mathrm{BC}$ risk. It was reported in a recent study that polymorphic site at $X R C C 1$ is playing a double role in $\mathrm{BC}$ with anti-tumour activity and promotion of metastasis [5].
However, XRCC2 mutation $\mathrm{BC}$ susceptibility requires further investigation [10].

\section{H. ATR}

ATR, also known as ataxia ATR encodes a protein that activates CHK1, TP53, and BRCA1 and RAD. Germline mutations in this gene confer increased risk of developing $\mathrm{BC}[36]$.

\section{I. $C D K 1$}

Cyclin-dependent kinase 1 (CDK1) governs the G2/M transition of the cell cycle. CDK1 is important on DNA damage response and it phosphorylates BRCA1. Any functional change in CDK1 results in deficient DNA damage response signalling and DNA repair by HR. CDK1 may interfere with DNA damage response and can increase the risk of tumour formation including BC [36].

\section{LOW PENETRANCE GENES}

Genome-wide association studies (GWAS) led to the identification of many low penetrance genes/alleles with elevated BC risk [16]. Low penetrance alleles are often single nucleotide polymorphisms (SNPs) and they act in a combinational polygenic manner for the development of BC in an individual. At least 33-40 of complex SNPs interactions are needed to explain a threefold increased BC risk [15]. Some frequent Low penetrance genes/alleles are explained below.

\section{A. ARLTSI}

ARLTS1 (ADP-ribosylation factor-like tumour suppressor gene) is a tumour suppressor gene encodes GTP-binding proteins which are involved in multiple cell regulatory functions including apoptosis. Mutation in this low penetrance gene associated with familial melanoma and chronic lymphocytic leukaemia. A nonsense mutation in ARLTS1 leads to truncated protein which cannot bind GTP. A germline substitution of adenine for guanine is associated with increased risk of $\mathrm{HBC}$ regardless of the $B R C A$ mutation status [38].

\section{B. $A B R A X A S$}

$A B R A X A S$ is also known as (ABRA1, CCDC98, or $F A M 175 A$ ) codes a protein. This protein is an important component of the BRCA1 holoenzyme complex as it binds to BRCA1 BRCT motifs via its phosphorylated C-terminus. Because of the strong association with BRCA1, ABRAXAS could be cancer susceptibility gene and may play a role in HBOC [10].

\section{C. $M D M 2$}


The protein encoded by $M D M 2$ binds to $\mathrm{p} 53$ and inhibits its function in the absence of stress. MDM2 also has p53independent effect on the repair of DS DNA. Polymorphism located in the promoter region $309 \mathrm{bp}$ downstream from intron one results in a base change (T309G) has been associate with overexpression of MDM2. This polymorphism accelerates tumour formation and associated with early-onset BC. MDM2 is overexpressed in many cancers. [38].

\section{PARP4}

The protein encoded polymerase family member 4 (PARP4) genes add ADP-ribose to proteins. Recent studies have found that PARP4 is mutated in patients having thyroid and $\mathrm{BC}$ suggesting germline mutations in this gene can increase the risk of $\mathrm{BC}[1,49]$.

\section{E. CASP8}

Chromosome $2 \mathrm{q} 33-\mathrm{q} 34$ is the genomic location of caspase 8 (CASP8). CASP8 is a cysteine protease involved in the initiation of apoptosis or programmed cell death in response to DNA damage [16]. Some SNPs in CASP8 was identified to confer a slightly increased risk of $\mathrm{BC}$ and consider as a $\mathrm{BC}$ lower penetrance susceptibility gene [10].

\section{F. NF1}

Ras/Raf/Erk signal transduction pathway is negatively regulated by Neurofibromin 1 (NF1). Mutations in this gene are associated with neurofibromatosis type 1 (NF1) and cancers including BC [36].

\section{G. FGFR2}

Fibroblast growth factor receptor 2 (FGFR2) gene located on chromosome 10q26 [16]. The FGFR2 rs2981582, rs2420946, and rs1219648 polymorphisms reported as modifiers of $\mathrm{BC}$ risk in non $B R C A 1 / 2$ carriers [36].

\section{H. LSP1}

Lymphocyte-specific protein 1 (LSPI) located on chromosome $11 \mathrm{p} 15.5$ [16]. This gene encodes an intracellular F-actin binding protein which has plays a role in the regulation of neutrophil motility and trans-endothelial migration. The LPS1 rs3817198 polymorphism has been reported to have a small increased risk of BC [36].

\section{I. $M A P 3 K 1$}

Mitogen-activated protein kinase 1 E3 ubiquitin-protein ligase $(M A P 3 K 1)$ located on chromosome 5q11.2 [16]. The protein encoded by this gene is important in cell signaling, proliferation and apoptosis [50]. MAP3K1 rs889312 polymorphism reported being associated with a small increased risk of familial and early-onset BC [36].

\section{J. TGFB1}

Transforming growth factor $\beta 1$ (TGFB1) gene mutations cause a disease condition called Camurati-Engelmann disease. The rs1982073 TGFB1polymorpysm has been reported to have a slightly increased risk of developing PRnegative $\mathrm{BC}[36]$.

\section{K. TOX3}

TOX high mobility group box family member 3 (TOX3) gene located on chromosome 16q12 [50]. TOX3 encodes a protein involves in alteration of chromatin structure and act as predicted to act as a transcription factor [50]. Polymorphism rs3803662 TOX3 reported having an increased risk of developing BC [36].

\section{VEGF}

The major function of vascular endothelial growth factor $(V E G F)$ is tumour angiogenesis. Genetic alterations in $V E G F$ reported having a functional influence of $\mathrm{BC}$ in BRCA mutation carriers [36].

\section{TNRC9}

TNRC9 is located on chromosome $16 \mathrm{q}$ and genetic variation in this gene associated with slightly increased the risk in developing BC [16].

\section{N. $H 19$}

H19 gene is located on $11 \mathrm{p}$ and SNPs in this locus associated with slightly increased in the risk of developing $\mathrm{BC}[16]$.

\section{O. ESR1}

Estrogen receptor 1 (ESRl) is located on chromosome 6q25.1 and polymorphism rs2046210 in ESR1 has been associated with slightly increased risk of developing $\mathrm{BC}$ [50]

\section{CONCLUSIONS}

Certain gene mutations and certain rare hereditary syndromes such as Lynch syndrome, Li-Fraumeni syndrome, Cowden Syndrome, ataxia-telangiectasia syndrome, Peutz-Jeghers syndrome, and Nijmegen breakage syndrome are associated with an increased risk of developing $\mathrm{BC}$. HBC predisposition is due to inheritable mutations tumour suppressor, DNA damage repair (DNA DS repair and DNA mismatch repair genes). Cancer risk due to mutations in these genes varies with the number of relatives affected and age of diagnosis of them. It was thought that the majority of $\mathrm{HBC}$ cases are due to the mutation in BRCA1 and BRCA2, well-studied tumour suppressor genes. However, the latest studies have found 
that only $20 \%-30 \%$ of HBCs are due to mutations in $B R C A 1$ or $B R C A 2$. Advancement in molecular genetics and linkage analysis many other HBC susceptibility genes (TP53, PTEN, STKII, CHEK2, ATM, PLAB 2 and BRIP2) haven has been identified with high and moderate penetrance. These genes are tumour suppressors and genes involved in DNA repair pathways. Completion of the human genome project and development of genome-wide association studies (GWAS) has paved the path to identify even more hereditary susceptibility genes/alleles with low penetrance. Low penetrance gene/alleles function in a complex combinatorial polygenic manner in an individual to develop BC.

Understanding the high, moderate and low penetrance gene mutations with elevated $\mathrm{BC}$ risk are important to design clinical test to identify individuals with a higher risk of developing $\mathrm{BC}$ at a younger age. Early identification of individuals at increased risk of $\mathrm{BC}$ may lead to better screening and treatment, prevention and improved overall survival benefit.

\section{CONFLICTS OF INTEREST}

The authors declare that there are no conflicts of interest

\section{REFERENCES}

[1] V. Trevino. (Augest 2019). Integrative genomic analysis identifies associations of molecular alterations to APOBEC and BRCA1/2 mutational signatures in breast cancer. Mol Genet Genomic Med. 7(8): e810. Available: https://doi.org/10.1002/mgg3.810

[2] B. Vogelstein, N. Papadopoulos, V. Velculescu, S. Zhou, L. A. Diaz and K. W. Kinzler. (March 2013). Cancer Genome Landscapes. Science. 339(6127). pp. 1546-1558. Available: https://doi.org/10.1126/science. 1235122

[3] T. Helleday, S. Eshtad and S. Nik-Zainal. (July 2014). Mechanisms underlying mutational signatures in human cancers. Nat Rev Genet. 15(9). pp. 585-598. Available: https ://doi.org/10.1038/nrg3729.

[4] N.D.W Dissanayake, "Clinical Characterization of a cohort of Sri Lankan families with inherited cancer syndrome", MSc, dissertation, University of Colombo, 2014.

[5] K. Kiwerska and K. Szyfter. (2019). DNA repair in cancer initiation, progression, and therapy - A double-edged sword. J Appl Genet. 60 (3-4) pp. 329-334. Available: https://doi.org/10.1007/s13353-01900516-9

[6] G. Lippi, C. Mattiuzzi and M. Montagnana. (July 2017). BRCA population screening for predicting breast cancer: for or against? Ann Transl Med. 5(13). pp. 275-275, Available: https://doi.org/10.21037/atm.2017.06.71

[7] Y. Wu, F. Liu, S. Luo, X. Yin, D. He, J. Liu, Z. Yue and J. Song. (July 2019).Co-expression of key gene modules and pathways of human breast cancer cell lines. Biosci Rep. 39 (7). Available: https://doi.org/10.1042/BSR20181925

[8] S. Malvia, S. A. R. Bagadi, D. Pradhan, C. Chintamani, A Bhatnagar, D. Arora, R. Sarin and S. Saxena. (July 2019). Study of Gene Expression Profiles of Breast Cancers in Indian Women. Sci Rep 9(10018). Available: https://doi.org/10.1038/s41598-019-462611 .

[9] A. Fernando, U. Jayarajah, S. Prabashani, E. Fernando and S. Seneviratne. (April 2018). Incidence trends and patterns of breast cancer in Sri Lanka: an analysis of the national cancer database. BMC Cancer. 18(482). Available: https://doi.org/10.1186/s12885-018-4408-4

[10] P. Apostolou and F. Fostira. (March 2013). Hereditary Breast Cancer: The Era of New Susceptibility Genes. BioMed Res Int Available: https://doi.org/10.1155/2013/747318

[11] N. Okumura, H. Yoshida, Y. Kitagishi, Y. Nishimura and S. Matsuda. (September 2011). Alternative splicings on p53, BRCA1 and PTEN genes involved in breast cancer. Biochem Biophys Res
Commun. 413(3). pp.395-399. https://doi.org/10.1016/j.bbrc.2011.08.098

Available:

[12] S. Shiovitz and L. A. Korde. (July 2015). Genetics of breast cancer: a topic in evolution. Ann Oncol. 26(7). pp. 1291-1299. Available: https://doi.org/10.1093/annonc/mdv022

[13] Z. Baretta, S. Mocellin, E. Goldin, O. Olopade and D. Huo. (October 2016). Effect of BRCA germline mutations on breast cancer prognosis. Medicine. 95(40). e4975. doi: $10.1097 / \mathrm{md} .0000000000004975$

[14] J. D. Fackenthal and O. I. Olopade. (December 2007). Breast cancer risk associated with BRCA1 and BRCA2 in diverse populations. Nat Rev Cancer. 7(12) pp. 937-948. Available: https://doi.org/10.1038/nrc2054

[15] K. N. Maxwell and K. L. Nathanson. (December 2013). Common breast cancer risk variants in the post-COGS era: a comprehensive review. Breast Cancer Res. 15(6):212. Available: https://doi.org/10.1186/bcr3591

[16] U. O. Njiaju and O. I. Olopade. (September 2012). Genetic Determinants of Breast Cancer Risk: A Review of Current Literature and Issues Pertaining to Clinical Application. Breast J. 18(5). pp. 436-442. Available: https://doi.org/10.1111/j.15244741.2012.01274.x

[17] A. W. Kurian, K. E. Kingham and J. M. Ford. (February 2015) Next-generation sequencing for hereditary breast and gynecologic cancer risk assessment. Curr Opin Obstet Gynecol. 27(1). pp. 23-33. Available: https://doi.org/10.1097/GCO.0000000000000141

[18] P. D. P Pharoah, A. Antoniou, M. Bobrow, R. L. Zimmern, D. F. Easton and B. A. J. Ponder. (May 2002). Polygenic susceptibility to breast cancer and implications for prevention. Nat Genet. 31(1). pp. 33-36, 2002. Available: https://doi.org/10.1038/ng853

[19] W. D. Foulkes. (November 2008). Inherited Susceptibility to Common Cancers. $N$ Engl J Med. 359(20). pp. 2143-2153. Available:https://doi.org/10.1056/NEJMra0802968

[20] K. N. Maxwell and S. M. Domchek. (September 2012). Cancer treatment according to BRCA1 and BRCA2 mutations. Nat Rev Clin Oncol. 9(9). pp. 520-528. Available: https://doi.org/10.1038/nrclinonc.2012.123

[21] A. Paul and S. Paul. (January 2014). The breast cancer susceptibility genes (BRCA) in breast and ovarian cancers", Front Biosci (Landmark Ed). 19(4). pp. 605-618. 20. Available: https://doi.org/10.2741/4230

[22] M. J. Larsen, M. Thomassen, A. N. Gerdes and T. A. Kruse. (October 2014). Hereditary Breast Cancer: Clinical, Pathological and Molecular Characteristics. Breast Cancer (Auckl). 8. pp.145-155. Available: https://doi.org/10.4137/BCBCR.S18715

[23] W. Zhang and Y. Yu. (September 2011). The Important Molecular Markers on Chromosome 17 and Their Clinical Impact in Breast Cancer. Int $J$ Mol Sci, 12(9). pp. 5672-5683. Available: https://doi.org/10.3390/ijms12095672

[24] F. Wang, Q. Fang, Z. Ge, N. Yu, S. Xu and X. Fan. (March 2012) Common BRCA1 and BRCA2 mutations in breast cancer families: a meta-analysis from systematic review. Mol Biol Rep. 39(3). pp. 2109-2118. Available: https://doi.org/10.1007/s11033-011-0958-0

[25] O. M. Valencia, S. E. Samuel, R. K. Viscusi, T. Riall, L. A. Neumayer and H. Aziz. (June 2017). The Role of Genetic Testing in Patients with Breast Cancer: A Review. JAMA Surg. vol. 152(6). pp. 589-594. Available: https://doi.org/10.1001/jamasurg.2017.0552.

[26] L. A. R. Oluwagbemiga, A. Oluwole and A. A. R. Kayode. (December 2012). Seventeen years after BRCA1: what is the BRCA mutation status of the breast cancer patients in Africa? - a systematic review", SpringerPlus. 1(1):83. Available: https://doi.org/10.1186/2193-1801-1-83

[27] M. Ratajska, E. Antoszewska, A. Piskorz, I. Brozek, A. Borg, H. Kusmierek, W. Biernat, and J. Limon. (2012). et al., "Cancer predisposing BARD1 mutations in breast-ovarian cancer families", Breast Cancer Res Treat. 131(1). pp.89-97. https://doi.org/10.1007/s10549-011-1403-8

[28] P. Economopoulou, G. Dimitriadis and A. Psyrri. (January 2015). Beyond BRCA: New hereditary breast cancer susceptibility genes. Cancer Treat Rev. 41(1), 1-8 https://doi.org/10.1016/j.ctrv.2014.10.008

[29] R. Roy, J. Chun and S. Powell. (December 2011). BRCA1 and BRCA2: different roles in a common pathway of genome protection. Nat Rev Cancer. 12(1). pp. 68-78. Available: https://doi.org/10.1038/nrc3181

[30] N. M. Davis, M. Sokolosky, K. Stadelman, S. L. Abrams, M. Libra, S. Candido et al.(July 2014). Deregulation of the EGFR/PI3K/PTEN/Akt/mTORC1 pathway in breast cancer: possibilities for therapeutic intervention. Oncotarget. 5(13). pp.4603- 
4650. Available: https://doi.org/10.18632/oncotarget.2209

[31] W. Zhang, A. Edwards, E. K. Flemington and K. Zhang (February 2017). Significant Prognostic Features and Patterns of Somatic TP53 Mutations in Human Cancers. Cancer Inform.16. Available: https://doi.org/10.1177/1176935117691267

[32] J. Huszno and E. Grzybowska. (July 2018). TP53 mutations and SNPs as prognostic and predictive factors in patients with breast cancer. Oncol Lett. 16(1). pp.34-40. Available: https://doi.org/10.3892/ol.2018.8627

[33] A. Patocs, L. Zhang, Y. Xu, F. Weber, T. Caldes, G. L. Mutter, P. Platzer and C. Eng. Breast-Cancer Stromal Cells withTP53Mutations and Nodal Metastases. $N$ Engl J Med. 357(25). pp.2543-2551. https://doi.org/10.1056/NEJMoa071825

[34] M. Tischkowitz, B. Xia, N. Sabbaghian, J. S. Reis-Filho, N. Hamel, G. Li G, E. H. van Beers, L. Li, T. Khalil, L. A. Quenneville, A. Omeroglu, A. Poll, P. Lepage, N. Wong, P. M. Nederlof, A. Ashworth, P. N. Tonin, S. A. Narod, D. M. Livingston and W. D. Foulkes (April 2007). Analysis of PALB2/FANCN-associated breast cancer families. Proc Natl Acad Sci U S A.104 (16). pp.6788-93. Available: https://doi.org/10.1073/pnas.0701724104

[35] N. Jones, F. Bonnet, S. Sfar, M. Lafitte, D. Lafon, G. Sierankowski, V. Brouste, G. Banneau, C. Tunon de Lara, M. Debled, G MacGrogan, M. Longy and N. Sevenet. (July 2013). Comprehensive analysis of PTEN status in breast carcinomas. Int $J$ Cancer. 133(2) pp.323-3. Available: https://doi.org/10.1002/ijc.28021

[36] H. Kobayashi, S. Ohno, Y. Sasaki and M. Matsuura. (June 2013). Hereditary breast and ovarian cancer susceptibility genes (Review) Oncol Rep, 30(3). 1019-1029. https://doi.org/10.3892/or.2013.2541

[37] A. D. Skol, M. M. Sasaki and K. Onel. October 2016). The genetics of breast cancer risk in the post-genome era: thoughts on study design to move past BRCA and towards clinical relevance. Breas Cancer Res. 18(1):99. Available: https://doi.org/10.1186/s13058016-0759-4

[38] E. Akisik, H. Yazici and N. Dalay. (January 2011). ARLTS1, MDM2 and RAD51 gene variations are associated with familial breast cancer. Mol Bio Rep. 38(1) pp. 343-348, 2010. Available: https://doi.org/10.1007/s11033-010-0113-3

[39] A. R. Venkitaraman. (January 2002). Cancer Susceptibility and the Functions of BRCA1 and BRCA2. Cell. 108(2) pp.171-182. DOI 10.1016/s0092-8674(02)00615-3

[40] P. Peltomäki. Role of DNA Mismatch Repair Defects in the Pathogenesis of Human Cancer. J Clin Oncol. 21(6). pp. 1174-1179, March 2003.

[41] N. Tung, C. Battelli, B. Allen, R. Kaldate, S. Bhatnagar, K. Bowles, K. Timms, J. E. Garber, C. Herold, L. Ellisen, J. Krejdovsky, K. DeLeonardis, K. Sedgwick, K. Soltis, B. Roa, R. J. Wenstrup and A. R. Hartman. (January 2015). Frequency of mutations in individuals with breast cancer referred for BRCA1 and BRCA2 testing using next-generation sequencing with a 25-gene panel. Cancer, 121(1). pp. 25-33. Available: https://doi.org/10.1002/cncr.29010

[42] A. C. Antoniou, W. D. Foulkes and M. A. Tischkowitz. (October 2014). Breast-Cancer Risk in Families with Mutations in PALB2. $N$ Engl $J$ Med. 371(17). pp.1651-1652. Available: https://doi.org/10.1056/NEJMc1410673

[43] B. Decker, J. Allen, C. Luccarini, K. A. Pooley, M. Shah, M. K. Bolla, Q. Wang, S. Ahmed, C. Baynes, D. M. Conroy, J. Brown, R. Luben, E. A. Ostrander, P. D. Pharoah, A. M. Dunning and D. F. Easton (November 2017). Rare, protein-truncating variants in $A T M, C H E K 2$ and $P A L B 2$, but not $X R C C 2$, are associated with increased breast cancer risks. J Med Genet. 54(11). pp. 732-741. Available: https://doi.org/10.1136/jmedgenet-2017-104588

[44] A. Desrichard, Y. Bidet, N. Uhrhammer and Y. Bignon. (November 2011)CHEK2 contribution to hereditary breast cancer in nonBRCAfamilies. Breast Cancer Res. 13(6). Available: https://doi.org/10.1186/bcr3062

[45] A. W. Kurian, E Hughes, E. A. Handorf, A. Gutin, B. Allen, A. R. Hartman and M. J. Hall. (June 2017). Breast and Ovarian Cancer Penetrance Estimates Derived From Germline Multiple-Gene Sequencing Results in Women. JCO Precis Oncol, 1. pp. 1-12. DOI 10.1200/po.16.00066

[46] A. Venkateshwari, D. W. Clark, P. Nallari, C. Vinod, T. Kumarasamy, G. Reddy, A. Jyothy, M. V. Kumar, R. Ramaiyer and K. Palle. (March 2017). BRIP1/FANCJMutation Analysis in a Family with History of Male and Female Breast Cancer in India. J Breast Cancer. 20(1). pp.104-107. https://doi.org/10.4048/jbc.2017.20.1.104

[47] K. Heikkinen, K. Rapakko, S. H. Karppinen, H Erkko, S. Knuutila, T. Lundán, A. Mannermaa, A. L. Børresen-Dale, A. Borg, R. B. Barkardottir, J. Petrini, and R. Winqvist (August 2006). RAD50 and NBS1 are breast cancer susceptibility genes associated with genomic instability. Carcinogenesis, 27(8) pp. 1593-1599. Available: https://doi.org/10.1093/carcin/bgi360

[48] F. S. Hilbers, J. T. Wijnen, N. Hoogerbrugge, J. C. Oosterwijk, M. J. Collee, P. Peterlongo, P. Radice, S. Manoukian, I. Feroce, F. Capra, F. J. Couch, X. Wang, L. Guidugli, K. Offit, S. Shah, I. G. Campbell, E. R. Thompson, P. A. James, A. H. Trainer, J. Gracia, J Benitez, C. J. van Asperen and P. Devilee. (October 2012). Rare variants in XRCC2 as breast cancer susceptibility alleles. J Med Genet. 49(10). pp. 618-20. Available: https://doi.org/10.1136/jmedgenet-2012101191

[49] R. Das, S. Kundu, S. Laskar, Y. Choudhury and S. K. Ghosh. (July 2018). Assessment of DNA repair susceptibility genes identified by whole exome sequencing in head and neck cancer. DNA Repair(Amst). 66-67. pp. 50-63. Available: https://doi.org/10.1016/j.dnarep.2018.04.005

[50] N. Mavaddat, A. C. Antoniou, D. F. Easton and M. Garcia-Closas. (June 2010). Genetic susceptibility to breast cancer. Mol Oncol. 4(3). pp. 174-191. Available: https://doi.org/10.1016/j.molonc.2010.04.011

Pathima Fairoosa completed her MSc in Biochemistry and Molecular Biology, University of Colombo Sri Lanka (2019) and BSc in Biological Science, University of Ruhuna, Sri Lanka (2017)

She is a research Assistant in department of biochemistry and Molecular Biology, Faculty of Medicine, University of Colombo, Sri Lanka. Her research interest includes gene mutations and cancer risk in hereditary cancers.

Chamindri Witharana completed her PhD in Micro and Molecular Biology, University of Giessen (Justus Liebig University) Giessen, Germany (2013), MPhil in Biological Sciences and Biochemistry, School of Environmental Sciences, University of Wales, Swansea, United Kingdom (2009) and BSc (Hons) in Chemistry (Sp.), University of Colombo, Colombo, Sri Lanka (2006).

Dr Chamindri Witharana is a Senior Lecturer in Biochemistry and Molecular Biology at the Faculty of Medicine, University of Colombo, Sri Lanka. She has provided her expertise in Molecular Biology at both national and international level. Her main research interest is molecular and genetic basis of cancer 